\title{
Gestational diabetes mellitus is as innocent as you think?
}

\author{
Gulsum Uysal $^{1 *}$, Mehmet Serdar Kutuk ${ }^{2}$
}

\begin{abstract}
${ }^{1}$ Department of Obstetrics and Gynecology, Adana City Education and Research Hospital, Adana, Turkey
\end{abstract}
${ }^{2}$ Department of Obstetrics and Gynecology, Bezmialem Foundation University, Istanbul, Turkey

Received: 19 July 2018

Accepted: 31 July 2018

*Correspondence:

Dr. Gulsum Uysal,

E-mail: gulsumaykut@yahoo.com

Copyright: (C) the author(s), publisher and licensee Medip Academy. This is an open-access article distributed under the terms of the Creative Commons Attribution Non-Commercial License, which permits unrestricted non-commercial use, distribution, and reproduction in any medium, provided the original work is properly cited.

\begin{abstract}
Background: We aimed to compare fetal outcomes, fetal hypoxia, acidemia and maternal chracteristics including hemoglobin A1c, doppler indices between gestational diabetes mellitus (GDM) and pregestational diabetes mellitus (DM) among pregnant women treated with insulin.

Methods: Data of pregnant patients with diagnosis of pregestational diabetes (type 1 and 2) and GDM who were treated with insulin (GDM A2 in White classification) was retrospectively collected and compared. Patients with active chronic systemic disease, multiple pregnancies, lost to follow up and detected fetal malformations were exluded. Maternal characteristics, umbilical doppler indices and amnion fluid index, gestational age at delivery, delivery characteristics (including vaginal delivery, or cesarean section) and newborn characteristics such as birth weight, Apgar score and umblical cord $\mathrm{pH}$ were all recorded.

Results: A total of 130 patients (67 patients with GDM and 63 pregestational DM) were recruited to the study. There were no significant difference regarding type of delivery, fetal birth weight, umbilical cord $\mathrm{Hb}$ and gestational birth age. No other significant difference in frequency of low Apgar scores and fetal acidosis or metabolic acidosis were reported. HbA1c and blood glucose levels and insulin dosage were significantly statistically higher in pregestational group.

Conclusions: The frequency of fetal distress parameters and poor fetal outcome were similar between groups although pregestaional diabetic patients had higher HbA1c rates. Therefore, patients with GDM (A2) should be followed up as closely as pregestational (overt) diabetic patients.
\end{abstract}

Keywords: Fetal hypoxia, Gestational diabetes mellitus, Hemoglobin A1c, Pregestational diabetes

\section{INTRODUCTION}

Gestational diabetes mellitus (GDM) is a common multisystemic disease affecting $6-7 \%$ pregnancies in western countries. ${ }^{1,2}$ GDM is a type of carbohydrate intolerance with onset or first diagnosed during pregnancy depending on the diagnostic criteria used. ${ }^{3}$ Pregestational diabetes (diabetes mellitus type 1 and 2) is also one of the common chronic metabolic disorders resulting with four times relative risk for fetal death and higher risks of complications such as hypertension, preeclampsia, genital trauma and cesarean delivery.,4-6
Type 1 diabetes mellitus (DM) is a kind of pancreas $\beta$ cell destruction while type $2 \mathrm{DM}$ is characterized as insufficient insulin release leading insulin resistance. ${ }^{7}$ The antenatal follow-up in diabetic pregnant women is important to control blood glucose levels, treat chronic complications and to monitor the fetus. In addition to routine pregnancy antenatal follow up, glucose impairment is the most focused issue to manage and identify the complications of pregnancy in GDM patients.

It is well known that pregestational DM has higher congenital fetal malformations including caudal 
regression or cardiac diseases compared to GDM (typically have rare diabetes-related vasculopathy due to short exposure time of the disorder and late pregnancy onset). ${ }^{8}$ Moreover, pregestational diabetes would have a more severe glycemic disturbance and increased risk of both maternal and neonatal complications; however, little has been reported regarding differences in pregnancy outcomes between these groups. In this study, we aimed to compare fetal outcomes, fetal hypoxia, acidemia and maternal characteristics including hemoglobin A1c, doppler indices between GDM and pregestational DM among pregnant women treated with insulin.

\section{METHODS}

This retrospective cohort study was conducted between January 2014 and June 2015 at a tertiary referral Center in Kayseri, Turkey. Informed written consent was obtained from all participants. The study was approved by ethics committee of Erciyes School of Medicine. All the procedures followed were in accord with the ethical standards of the committee on human experimentation stated at the Declaration of Helsinki.

\section{Patients selection and study design}

Data of pregnant patients followed in our department with diagnosis of pregestational diabetes (type 1 and 2) and GDM who were treated with insulin (GDM A2 in White classification) was retrospectively collected and compared. Singleton pregnancies aged between 18-45 were included. Patients with active chronic systemic disease, lost to follow up and detected fetal malformations were exluded. Collected data included maternal characteristics (age, parity, pre-pregnancy body mass index (BMI)), gestational age at delivery, delivery characteristics (including vaginal delivery, or cesarean section) and newborn characteristics such as birth weight, Apgar score and umblical cord $\mathrm{pH}$. Gestational age was defined by the number of weeks since the last menstrual period or the ultrasound assessment of crown-rump length if discordance was recognized. Maternal laboratory values including blood glucose, Hemoglobin Alc, thyroid stimulating hormone (TSH) and insulin doses were also recorded.

Due to our clinic protocol, blood glucose screening test was performed at 24-28 weeks with $50 \mathrm{~g}$ glucose loading test with a $135-\mathrm{mg} / \mathrm{dL}$ cutoff point. If the $50 \mathrm{~g}$ screening was positive, then a diagnostic $100 \mathrm{~g}$ oral glucose tolerance test (OGTT) was performed according to Carpenter and Coustan (CC) criteria. $^{9}$ If blood glucose level was above $190 \mathrm{mg} / \mathrm{dL}$ at 50 gr glucose test or two or more values were above the cutoff levels in the OGTT, these women were considered to have pregestational DM. 2-hours postprandial blood glucose profile was assessed accompanying diet treatment $(30 \mathrm{kkal} / \mathrm{kg})$ every 2 weeks. All diabetic pregnant women in this study were hospitalized at 37 weeks and monitored by nonstress test. Estimated fetal weight, amniotic fluid volume and fetal umbilical Doppler examination of all patients were evaluated.

In uncomplicated cases, either elective induction of labor or cesarean section was scheduled between 38 weeks 3 days and 39 weeks. After the delivery, an umbilical cord segment was double-clamped, and a venous blood gas sample was obtained using $1 \mathrm{~mL}$ heparinized syringe by an assistant and sent immediately for analysis in our intensive care laboratory. Patients with acute fetal distress, umbilical cord prolapsus, and ablatio placentae were not included in the study. Umbilical venous $\mathrm{pH}$ and base deficit cutoff levels of 7.23 and $6.3 \mathrm{mmol} / \mathrm{L}$, were used respectively, which corresponds to more than $1 \%$ probability of fetal acidemia and metabolic acidosis. ${ }^{10,11}$

All patients with newly diagnosed GDM during pregnancy were checked with 75-gr OGTT six weeks after delivery to confirm the diagnosis.

\section{Statistical analysis}

The clinical features of both groups were compared with the Statistical Package for Social Sciences (SPSS) for Windows, version 18.0 (SPSS Inc. IL, USA). The Shapiro-Wilk and Kolmogorov Smirnov tests were used to test for the distribution of data. Normally distributed baseline characteristics were presented as mean \pm standard deviation, and abnormally distributed data were presented as median (min-max). To assess the differences in variables between groups, the independent $\mathrm{t}$ test was used. Results with non-normal distribution, KruskalWallis, Mann-Whitney U-test and Bonferroni correction were used. Values of $\mathrm{p}<0.05$ was accepted as statistically significant.

\section{RESULTS}

A total of 130 patients (67 patients with GDM and 63 pregestational DM) were recruited to the study. There was no significant difference regarding age, gravida, parity and BMI between groups. Ultrasound indices (Umb Pi, Umb s/d and amnion fluid index) of groups were also similar. HbA1c and blood glucose levels were significantly statistically higher in pregestational group while TSH values were similar. Insulin dosage needed for treatment was also higher in pregestational group as expected. There was no significant difference regarding type of delivery, fetal birth weight, umbilical cord $\mathrm{Hb}$ and gestational birth age. No other significant difference in frequency of low Apgar scores and fetal acidosis or metabolic acidosis were reported. Comparision of maternal and fetal chracteristics between groups were summarized in Table 1. Cesarean delivery rates were high in both groups. There was neither fetal or maternal mortality nor severe ketoacidosis episodes.

There were 18 patients with type 1 and 45 patients with type 2 in pregestatinal DM group. The mean time (year) 
of diabetic history was 8.8 and 4.6 in type 1 and 2 , respectively.

Table 1: Comparison of maternal and fetal characteristics between groups.

\begin{tabular}{|c|c|c|c|}
\hline & $\begin{array}{l}\text { GDM } \\
(n=67)\end{array}$ & $\begin{array}{l}\text { Pregestational } \\
\text { DM } \\
\text { (type } 1 \text { and } 2 \\
\text { diabetes) }(n=63)\end{array}$ & $\begin{array}{l}P \\
\text { value }\end{array}$ \\
\hline Age (y) & $33.8( \pm 5.9)$ & $32.9( \pm 7.1)$ & 0.4 \\
\hline Gravida & $3.5( \pm 1.7)$ & $3.6( \pm 2.0)$ & 0.8 \\
\hline Parity & $2.1( \pm 1.4)$ & $2.3( \pm 1.7)$ & 0.4 \\
\hline BMI $\left(\mathrm{kg} / \mathrm{m}^{2}\right)$ & $33.7( \pm 7.2)$ & $33.8( \pm 5.0)$ & 0.8 \\
\hline Insulin dosage* & $16(4-130)$ & $40(4-160)$ & 0.002 \\
\hline $\mathrm{HbA1c}$ & $5.4( \pm 0.9)$ & $5.9( \pm 1.0)$ & 0.005 \\
\hline TSH & $1.7( \pm 1.0)$ & $1.9( \pm 1.3)$ & 0.2 \\
\hline $\begin{array}{l}\text { Blood glucose } \\
\text { (mg/dL) }\end{array}$ & $\begin{array}{l}105.2 \\
( \pm 14.5)\end{array}$ & $110.7( \pm 15.5)$ & 0.05 \\
\hline Umb Pi & $0.9( \pm 0.2)$ & $0.96( \pm 0.2)$ & 0.1 \\
\hline Umb s/d* & $2.2(1.4-5.3)$ & $2.5(1.6-7.6)$ & 0.9 \\
\hline $\begin{array}{l}\text { Amnion fluid } \\
\text { index (AFI) (ml) }\end{array}$ & $185( \pm 7.1)$ & $233( \pm 21.8)$ & 0.09 \\
\hline $\begin{array}{l}\text { polyhydramnios } \\
(\text { AFI }>240 \mathrm{~mm})\end{array}$ & 17 & 19 & 0.5 \\
\hline \multicolumn{4}{|l|}{ Type of delivery } \\
\hline Vaginal delivery & 12 & 10 & \multirow{2}{*}{0.7} \\
\hline Cesarean & 55 & 53 & \\
\hline $\begin{array}{l}\text { Fetal birth } \\
\text { weight (gr) }\end{array}$ & $\begin{array}{l}3509 \\
( \pm 527)\end{array}$ & $3633( \pm 556)$ & 0.2 \\
\hline $\begin{array}{l}\text { Umb cord } \mathrm{Hb} \\
(\mathrm{g} / \mathrm{dL})\end{array}$ & $15.6( \pm 1.6)$ & $15.8( \pm 1.6)$ & 0.5 \\
\hline $\begin{array}{l}\text { Gestational } \\
\text { birth age }(\mathrm{w})\end{array}$ & $38.5( \pm 0.4)$ & $38.4( \pm 0.3)$ & 0.2 \\
\hline $\begin{array}{l}\text { 1min Apgar } \\
\text { score } \leq 7\end{array}$ & 7 & 7 & 0.9 \\
\hline $\begin{array}{l}5 \text { min Apgar } \\
\text { score } \leq 7\end{array}$ & 1 & 0 & 0.3 \\
\hline $\begin{array}{l}\text { fetal acidosis } \\
\text { venous } \mathrm{pH}<7.23\end{array}$ & 9 & 7 & 0.6 \\
\hline $\begin{array}{l}\text { metabolic } \\
\text { acidosis (base } \\
\text { deficit }>6.3 \\
\text { mmol/L) }\end{array}$ & 18 & 11 & 0.1 \\
\hline
\end{tabular}

\section{DISCUSSION}

This study implies that patients diagnosed with GDM and needed insulin therapy should be followed up as pregestational DM during antenatal period. Although blood glucose and $\mathrm{HbA1C}$ values were significantly different between pregnancies with GDM(A2) and pregestational DM, similar results were obtained in terms of fetal distress parameters.

In a recent study, they analyzed and compared the course and outcome of pregnancy in the patients with diabetes in relation to the group of healthy women regarding preterm delivery, perinatal morbidity and mortality. ${ }^{12}$ They also evaluated pregnancy outcomes in the patients with preexisting diabetes type 1 and the patients with gestational and diabetes type 2 . Their study resulted that a higher incidence of perinatal fetal morbidity (hypoglycemia, jaundice, respiratory distress syndrome) in the patients with type 1, type 2 and GDM than in the healthy controls. Moreover, there was a higher incidence of cesarean section in the patients with type 1 diabetes than in those with type 2, gestation diabetes and healthy controls. Although there was no significant difference in the frequency of preterm delivery, they mentioned that poorer glycaemic control resulting higher values of HbA1c in third trimester was related to preterm delivery. ${ }^{12}$ In present study all patients were treated with insulin and we compared antenatal ultrasound (amnion fluid index (AFI), umbilical doppler etc.) and peri and postnatal maternal and fetal outcomes in patients with GDM and pregestational DM including type 1 and 2 . We did not have control groups since we wanted to compare GDM A2 and pregestational diabetic results. It is well known that diabetes affects pregnancy in one way or another.

In another study, consequences of gestational and pregestational diabetes on placental function and birth weight were evaluated. ${ }^{13}$ It was said that the placental structure was altered in pregestational and GDM. In addition, it was shown that oxygen supply was reduced in the maternal-placental in diabetic patients. ${ }^{14}$ Due to impaired oxygen supply, more fetal oxygen was required. Low fetal oxygen levels affect and accelerate the transcription synthesis of proangiogenic factors such as leptin, vascular endothelial growth factor (VEGF) or fibroblast growth factor 2 (FGF2). ${ }^{15,16}$ Therefore, both types of diabetes (GDM and in type $1 \mathrm{DM}$ ) were characterized by increased vascularisation. ${ }^{14}$ In present results, HbA1c and blood glucose levels were significantly statistically higher in pregestational group while fetal outcomes were similar regarding fetal distress. This may be explained by other preangiogenic factors mentioned above. In fact, we could not trust $\mathrm{HbA} 1 \mathrm{c}$ levels only due to this metabolism.

Tan et al. evaluated abnormal umbilical artery resistance index (UARI) in 50 randomly selected diabetic patients and a matched control group of 50 non-diabetic pregnancies. ${ }^{17}$ They showed that abnormal UARI on Doppler study in diabetic pregnancy was not associated with a significantly higher incidence of than non-diabetic pregnancy. Authors have also performed umbilical doppler in all patients at least once per week, beginning from 36 weeks' gestation and could not find any difference between groups. Umbilical doppler parameters including Umb Pi and Umb s/d were not a useful tool to predict subsequent fetal outcome in diabetic pregnancies.

In our study, there was no significant difference among AFI between groups. In fact, there was no other significant differences in frequency of polyhydramnios (AFI $>240 \mathrm{ml}$ ). Idris et al. revealed that pregestational 
diabetic pregnancy with polyhydramnios was associated with poor diabetic control and resulting with significant increase in adverse perinatal outcome in these pregnancies, apart from a higher iatrogenic preterm birth rate. ${ }^{18}$ In present study, there was no significant difference regarding fetal distress parameters and poor fetal outcome between groups even though higher HbA1c rates in pregestational diabetic patients. We think that in studies with larger numbers, polyhydramnios scores may be different.

Importantly, a limitation of current study is that it included only diabetic women treated with insulin. The second, the small sample size of cases with low apgar scores presented a limitation to the analyses of the data collected. However, a particular strength of the present study was that this was the first study investigating and comparing maternal characteristics including doppler and laboratory parameters and fetal outcome between GDM (A2) and pregestational diabetes.

In conclusion, the frequency of fetal distress parameters and poor fetal outcome were similar between groups although pregestational diabetic patients had higher HbA1c rates. Therefore, patients with GDM (A2) should be followed up as closely as pregestational (overt) diabetic patients and careful attention should be paid to end organ damage.

\section{Funding: No funding sources}

Conflict of interest: None declared

Ethical approval: The study was approved by the Institutional Ethics Committee

\section{REFERENCES}

1. Committee on Practice Bulletins- Obstetrics. Practice bulletin no. 180: gestational diabetes mellitus. Obstet Gynecol. 2017;130:17-37.

2. Erem C, Kuzu UB, Deger O, Can G. Prevalence of gestational diabetes mellitus and associated risk factors in Turkish women: the Trabzon GDM Study. Arch Med Sci. 2015;4:724-35.

3. Köşüş A, Köşüş N, Turhan NÖ. Gestational diabetes: comparision of the carpenter and the coustan thresholds with the new thresholds of Turkish women and implications of variations in diagnostic criteria. J Matern Fetal Neonatal Med. 2012;25(6):616-22.

4. Tennant PWG, Glinianaia SV, Bilous RW, Rankin J, Bell R. Pre-existing diabetes, maternal glycated haemoglobin, and the risks of fetal and infant death: A population-based study. Diabetologia. 2014;2:285-94.

5. Mitanchez D. Fetal and neonatal complications of gestational diabetes: perinatal mortality, congenital malformations, macrosomia, shoulder dystocia, birth injuries, neonatal outcomes. J Gynecol Obstet Biol Reprod (Paris). 2010;39:189-99.

6. Yogev Y, Xenakis EM, Langer O. The association between preeclampsia and the severity of gestational diabetes: The impact of glycemic control. Am J Obstet Gynecol. 2004;5:1655-60.

7. American Diabetes Association. Diagnosis and classification of diabetes mellitus (position statement). Diabetes Care. 2009;32:62-7.

8. Eidem I, Stene LC, Henriksen T, Hanssen KF, Vangen $\mathrm{S}$, Vollset SE, et al. Congenital anomalies in newborns of women with type 1 diabetes: nationwide populationbased study in Norway, 1999-2004. Acta Obstet Gynecol Scand. 2010;11:1403-11.

9. Carpenter MW, Coustan DR. Criteria for screening tests for gestational diabetes. Am J Obstet Gynecol. 1982;7:768-73

10. Cantu J, Szychowski JM, Li X, Biggio J, Edwards RK, Andrews W, et al. Predicting fetal acidemia using umbilical venous cord gas parameters. Obstet Gynecol. 2014;5:926-32.

11. Victory R, Penava D, da Silva O, Natale R, Richardson B. Umbilical cord $\mathrm{pH}$ and base excess values in relation to neonatal morbidity for infants delivered preterm. Am J Obstet Gynecol. 2003;3:803-7.

12. Mitrović M, Stojić S, Tešić DS, Popović D, Rankov O, Naglić DT, et al. The impact of diabetes mellitus on the course and outcome of pregnancy during a 5-year follow-up. Vojnosanit Pregl. 2014;10:907-14.

13. Vambergue A, Fajardy I. Consequences of gestational and pregestational diabetes on placental function and birth weight. World J Diabetes. 2011;11:196-203.

14. Madsen H, Ditzel J. Blood-oxygen transport in first trimester of diabetic pregnancy. Acta Obstet Gynecol Scand. 1984;4:317-20.

15. Jośko J, Mazurek M. Transcription factors having impact on vascular endothelial growth factor (VEGF) gene expression in angiogenesis. Med Sci Monit. 2004;10:89-98

16. Black SM, DeVol JM, Wedgwood S. Regulation of fibroblast growth factor-2 expression in pulmonary arterial smooth muscle cells involves increased reactive oxygen species generation. Am J Physiol Cell Physiol. 2008;1:345-54.

17. Tan AE, Norizah WM, Rahman HA, Aziz BA, Cheah FC. Umbilical artery resistance index in diabetic pregnancies: the associations with fetal outcome and neonatal septal hypertrophic cardiomyopathy. J Obstet Gynaecol Res. 2005;4:296-301.

18. Idris N, Wong SF, Thomae M, Gardener G, McIntyre DH. Influence of polyhydramnios on perinatal outcome in pregestational diabetic pregnancies. Ultrasound Obstet Gynecol. 2010;3:338-43.

Cite this article as: Uysal G, Kutuk MS. Gestational diabetes mellitus is as innocent as you think? Int $\mathbf{J}$ Reprod Contracept Obstet Gynecol 2018;7:3526-9. 